\title{
Rancang Bangun Alat Pendeteksi NOx dan CO Berbasis Notifikasi Via Telegram dan Suara
}

\author{
Mutiara Asmazori, Nini Firmawati * \\ Jurusan Fisika, FMIPA Universitas Andalas Limau Manis Kec. Pauh, Kota Padang, Sumatera Barat 25163, Indonesia
}

\section{ARTICLE INFORMATION}

Received: July $7^{\text {th }}, 2021$

Revised: August $21^{\text {st }}, 2021$

Available online: September $30^{\text {th }}, 2021$

\section{KEYWORDS}

Biogas analyzer, nitrogen oxide gas, carbon monoxide gas, MQ-135 sensor, MQ-7 sensor.

\section{CORRESPONDENCE}

Nini Firmawati

E-mail: ninifirmawati@sci.unand.ac.id

\section{A $\quad$ B $\quad \mathbf{S}$ T $\mathbf{R}$ A $\mathbf{C}$ T}

The design of NOx and CO detectors based on notifications via telegram and voice has been carried out. This detector consists of a gas sensor MQ-135 as a nitrogen oxide detector and an MQ-7 sensor as a carbon monoxide detector. Data processing is carried out using an ESP32 microcontroller which can send results to a telegram bot and play sound using speakers connected to the ISD 1820 sound module. The tool made can send notifications if the concentration of nitrogen oxides and carbon monoxide exceeds 50 ppm. The test is carried out by burning waste to produce smoke. Burning smoke contains various gases and particles that are harmful to the body. The characterization of the MQ135 sensor was carried out by comparing the data obtained from the ISPU to measure nitrogen oxide gas and producing an error value of $9.09 \%$. Meanwhile, the characterization of the MQ-7 sensor was carried out using a biogas analyzer and resulted in an error ratio of $3.26 \%$. These results prove that the tools that have been designed can work well

\section{PENDAHULUAN}

Pencemaran udara adalah terdapatnya unsur atau zat berbahaya dalam atmosfir yang dapat menimbulkan kerusakan terhadap lingkungan hidup serta dapat menimbulkan gangguan kesehatan pada manusia. Pencemaran udara dapat dihasilkan dari emisi kendaraan bermotor, emisi gas pabrik industri, kebakaran hutan, dan lainnya. Seiring dengan meningkatnya isu pencemaran udara, Direktorat Pengendalian Pencemaran Udara (PPU) yang berada dibawah naungan Kementerian Lingkungan Hidup Indonesia membuat peralatan pemantauan kualitas udara ambien yang ditujukan untuk mengetahui kualitas udara pada suatu daerah/kota pada waktu tertentu. Hasil dari pemantauan ini disampaikan dalam bentuk Indeks Standar Pencemaran Udara (ISPU). Tahun 2020, KLHK mengeluarkan peraturan terbaru mengenai Perhitungan dan Pelaporan Serta Informasi Indeks Standar Pencemaran Udara. Perhitungan ISPU dilaukan pada 7 parameter yaitu $\mathrm{PM}_{10}, \mathrm{PM}_{2.5}, \mathrm{NO}_{2}, \mathrm{SO}_{2}, \mathrm{CO}, \mathrm{O}_{3}$.

\section{Nitrogen Oksida}

NOx merupakan sebutan untuk penggunaan $\mathrm{NO}$ dan $\mathrm{NO}_{2}$. Pencemaran udara oleh NOx dipengaruhi dari proses pembakaran bersuhu tinggi di pabrik sekitar 50\%, pembakaran bensin dan solar sekitar $40 \%$ serta pembakaran sampah padat dan hutan sekitar $10 \%$. Beberapa gejala keracunan yang disebabkan oleh gas NOx adalah iritasi paru-paru, melukai sistem pernafasan, menurunkan visibilitas atmosfer, penyebab hujan asam serta memperberat kerja jantung. Nitrogen oksida mampu mambatasi kadar oksigen dalam darah dan bila bertemu uap air dalam tubuh akan membentuk $\mathrm{HNO}_{3}$, hal ini menyebabkan rasa perih pada mata dan saluran pernafasan. Pengaruh 3,5 ppm $\mathrm{NO}_{2}$ terhadap tanaman akan menyebabkan nekrosis, sedangkan 800 ppm dalam waktu kurang dari 29 menit menyebab 100\% kematian hewanhewan yang diuji [2].

\section{Karbon Monoksida}

Karbon monoksida mampu mengikat sel darah merah lebih kuat dibandingkan dengan oksigen. Karbon monoksida memiliki daya ikat 250 kali lebih cepat dari oksigen. Jika karbon monoksida terhirup, maka CO tersebut akan bersenyawa dengan hemoglobin ( $\mathrm{Hb})$ dalam darah dan terbentuk karboksi hemoglobin $(\mathrm{COHb})$ yang dapat menghambat asupan oksigen dalam darah. Menurut OSHA (Occupatonal safety and health administration) paparan gas $\mathrm{CO}$ yang dianjurkan adalah $35 \mathrm{ppm}$ dalam waktu 8 jam. Paparan gas $\mathrm{CO}$ yang terjadi dalam waktu lama dapat menyebabkan Polisitemia. Salah satu gejala polisitemia adalah peningkatan warna kulit (sering kemerah-merahan) yang disebabkan oleh peningkatan hemoglobin. Bila hemoglobin mengikat karbon monoksida, maka hemoglobin tidak dapat mengikat oksigen lagi. Kondisi ini dapat menyebabkan kematian akibat keracunan gas $\mathrm{CO}$. 
ISPU

Peraturan Menteri Lingkungan Hidup Dan Kehutanan Republik Indonesia nomor P.14/MENLHK/SEKJEN/KUM.1.7.2020 tentang indeks standar pencemaran udara (ISPU) menjelaskan bahwa ISPU adalah angka yang tidak mempunyai satuan yang menggambarkan kondisi mutu udara ambien di lokasi tertentu, yang didasarkan kepada dampak terhadap kesehatan manusia, nilai estetika dan makhluk hidup lainnya. Indeks standar pencemaran udara di pantau pada Stasiun Pemantau Kualitas Udara Ambien dan dilakukan secara terus-menerus serta datanya dapat dipantau secara langsung.

Tabel 1 Kategori angka rentang ISPU

\begin{tabular}{|l|c|c|}
\hline \multicolumn{1}{|c|}{ Kategori } & Status warna & $\begin{array}{c}\text { Angka Rentang } \\
(\mathrm{ppm})\end{array}$ \\
\hline Baik & Hijau & $1-50$ \\
\hline Sedang & Biru & $51-100$ \\
\hline Tidak Sehat & Kuning & $101-200$ \\
\hline Sangat Tidak Sehat & Merah & $201-300$ \\
\hline Berbahaya & Hitam & $\geq 300$ \\
\hline
\end{tabular}

\section{Sensor MQ-135}

Sensor MQ-135 merupakan jenis sensor yang umum digunakan untuk air quality control. Sensor ini dapat mendeteksi gas ammonia $\left(\mathrm{NH}_{3}\right)$, nitrogen oksida $(\mathrm{NO})$, alkohol, benzene, asap, dan $\mathrm{CO}_{2}$. Sensor MQ-135 memiliki cakupan deteksi yang luas, dengan respon alat yang cepat dan sensitivitas tinggi. Sensor gas ini disusun oleh tabung keramik mikro AL2O3, lapisan sensitif dari timah dioksida ( $\mathrm{SnO} 2)$, sedangkan elektroda dan pemanas ke kerak yang terbuat dari plastik dan jaring stainless steel.

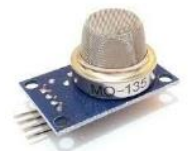

Gambar 1. Sensor MQ-135

\section{Sensor MQ-7}

Sensor gas MQ-7 merupakan sensor mendeteksi karbon monoksida (CO). Sensor gas MQ-7 ini mempunyai kelebihan sensitifitas yang tinggi terhadap karbon monoksida, stabil, dan usia pakai yang lama. Bentuk fisik dari sensor MQ-7 dapat dilihat pada Gambar 2.

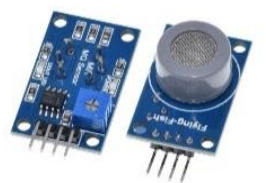

Gambar 2. Sensor MQ-7

\section{Modul Suara ISD1820}

Modul ISD 1820 adalah modul yang dapat digunakan untuk merekam suara dan memutar kembali suara yang direkam dengan menggunakan media penyimpanan terintegrasi (nonvolatile memory). Modul ini terintegrasi dalam chip tunggal ISD1820. Durasi perekaman suara menggunakan modul ini adalah 8 hingga 20 detik. Modul ISD1820 dilengkapi dengan microfon, tombol perekam suara (REC), tombol playback untuk memutar seluruh rekaman (PLAYE) serta tombol PLAYL yang hanya memutar hasil suara rekaman selama tombol tersebut ditekan. Modul ini berisi komponen-komponen yang dibutuhkan

dalam pengoperasian IC ISD 1820 serta tombol yang digunakan untuk recording dan playback, sehingga modul ini dapat digunakan hanya dengan menambahkan sumber tegangan saja. Bentuk fisik modul ISD 1820 ini dapat dilihat pada Gambar 3.

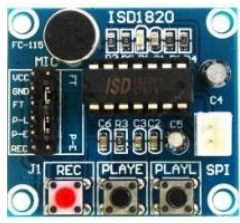

Gambar 4. Modul ISD 1820

Spesifikasi dari modul ISD1820:

- Chip utama

- Modul papan rangkaian

- Tegangan kerja

- Pengeras suara

- Mikrofon terdapat pada papan modul
: ISD1820

$38 \mathrm{~mm} \times 42,5 \mathrm{~mm}$

: DC 3 5V

$8 \mathrm{Ohm}, 0.5 \mathrm{~W}$

ESP32

ESP32 ini dirancang untuk dapat digunakan pada aplikasi seluler, perangkat elektronik dan Internet of Thing (IoT). Mikrokontroler ini dapat digunakan pada daya yang rendah dan mengunakan lowduty cycle yang dapat meminimalkan energi yang dikeluarkan oleh chip. ESP32 adalah mikrokontroler yang terintegrasi sehingga dapat digunakan pada Wi-Fi dan Bluetooth IoT disertai oleh 20 komponen eksternal. Bentuk fisik dari ESP32 dapat dilihat pada Gambar 5 .

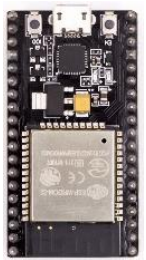

Gambar 5. Bentuk fisik ESP32

\section{METODOLOGI PENELITIAN}

\section{Rancangan Alat}

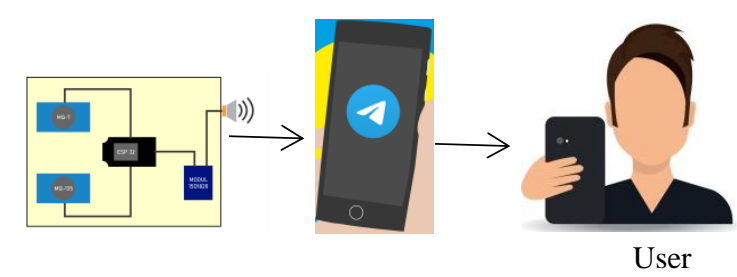

Gambar 6. Skema Rancangan Alat

Berdasarkan Gambar 6. Kotak yang dimaksud terdiri atas sensor MQ-135, sensor MQ-7, modul ISD 1820 beserta speaker, dan ESP32. Sensor MQ-135 digunakan untuk mendeteksi konsentrasi gas nitrogen oksida, sedangkan sensor MQ-7 digunakan untuk mendeteksi konsentrasi gas karbon monoksida, konsentrasi tersebut kirim dan di olah menggunakan mikrokontroler ESP32. Saat pengolahan jika konsentrasi gas NOx dan CO melebihi 50 ppm, maka data konsentrasi dikirimkan ke telegrambot dan muncul notifikasi pada smartphone melalui mikrokontroler ESP32.

\section{Perancangan Perangkat Keras}

Perancangan perangkat keras ini terdiri dari pengujian alat serta karakterisasi sensor. Pengujian alat berupa pengujian ESP32, dan 
pengujian modul suara ISD 1820. Karakterisasi sensor digunakan pada sensor MQ-135 dan sensor MQ-7.

\section{Pengujian ESP32}

Pengujian ESP32 dilakukan dengan menghubungkan ESP32 menggunakan kabel USB ke sumber daya. Pengujian pertama untuk ESP32 menggunakan Wi-Fi dilakukan dengan memasukkan nama serta password Wi-Fi pada program pada Arduino IDE. Sedangkan untuk pengujian kedua ESP32 dengan mengirimkan chat pada telegram bot yang telah disediakan.

\section{Pengujian Modul ISD 1820}

Pengujian yang dilaksanakan untuk mengetahui waktu maksimal perekaman suara menggunakan modul ISD1820

\section{Karakterisasi Sensor MQ-135}

Sensor MQ-135 adalah sensor gas yang mampu mendeteksi nitrogen oksida pada udara. Karakterisasi sensor MQ-135 dilakukan dengan membandingkan nilai konsentrasi gas nitrogen oksida terhadap nilai pada ISPU.

\section{Karakterisasi Sensor $M Q-7$}

Sensor MQ-7 adalah sensor gas yang mampu mendeteksi karbon monoksida pada udara. Karakterisasi sensor MQ-7 dilakukan dengan membandingkan nilai konsentrasi gas karbon monoksida terhadap Biogas Analyzer.

\section{Rancangan Proses}

Rancangan proses yang dilakukan dapat dilihat pada Gambar 8 . sebagai berikut :

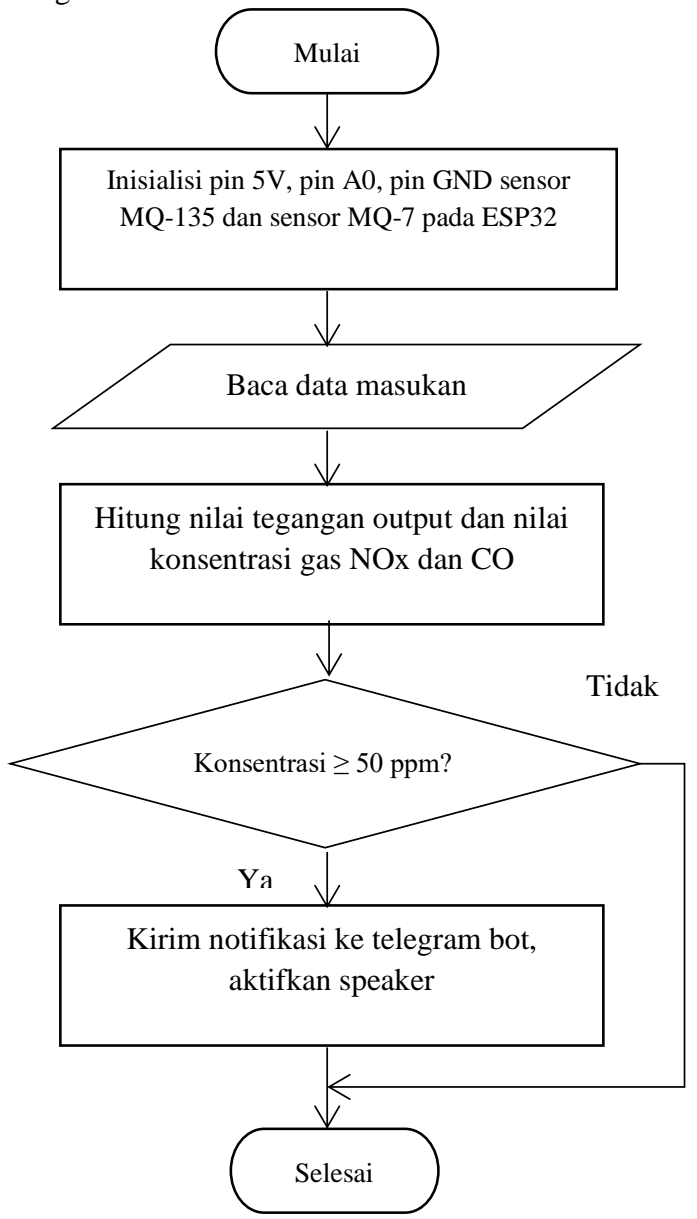

Gambar 8. Diagram alir program
Proses perancangan sistem deteksi gas NOx dan $\mathrm{CO}$ berbasis notifikasi via telegram dan suara dilakukan dengan menggunakan program bahasa $\mathrm{C}$ sebagai metode pengolah data yang didapatkan dari hasil kerja sensor MQ-135 dan MQ-7. Diagram alir perancangan Prototype ini dimulai dengan menginisiasi pin ESP32 yang dihubungkan dengan sensor MQ-135 dan MQ-7. Ketika sensor mendeteksi konsentrasi karbon monoksida dan nitrogen oksida dengan nilai dibawah 50 ppm, maka tidak akan ada notifikasi telegram dan pemberitahuan melalui speaker yang akan tersampaikan. Konsentrasi gas karbon monoksida maupun nitrogen oksida melebihi 50 ppm maka akan muncul notifikasi telegram yang menyatakan level pencemaran udara, nilai konsentrasi karbon monoksida dan nitrogen oksida. Pemberitahuan melalui speaker akan tersampaikan jika konsentrasi salah satu gas tersebut melebihi $50 \mathrm{ppm}$, saat konsentrasi melebihi nilai tersebut maka akan memberikan output high yang merupakan program perintah untuk modul suara ISD1820 untuk mengaktifkan speaker dan suara peringatan "konsentrasi gas no dan co melebihi batas sehat".

\section{HASIL DAN PEMBAHASAN}

Perancangan alat deteksi gas nitrogen oksida dan karbon monoksida ini dilakukan untuk mengetahui alat yang dirancang dapat berfungsi dengan baik atau tidak. Hasil yang didapatkan dari setiap karakterisasi alat serta pengujian alat dibandingkan dengan landasan teori yang berhubungan dengan perangkat yang digunakan. Perancangan alat deteksi gas nitrogen oksida dan karbon monoksida ini menggunakan sensor MQ-135, sensor MQ7, mikrokontroler ESP32 serta modul ISD1820.

\section{Karakterisasi Sensor MQ-135}

Pengujian sensor MQ-135 bertujuan agar dapat mengetahui pengaruh sensor dengan memberikan variasi gas nitrogen oksida (NOx). Datasheet pada MQ-135 menjelaskan untuk melakukan pemanasan sensor selama 24 jam agar gas yang terdapat dalam sensor dapat dibersihkan. Variasi dari kadar gas nitrogen oksida menghasilkan nilai tegangan output. Hubungan variasi nitrogen oksida dengan tegangan output dapat dilihat pada Tabel 1.

Tabel 4.1 Hubungan variasi konsentrasi gas nitrogen oksida dan tegangan keluaran sensor MQ-135

\begin{tabular}{ccc}
\hline No & $\begin{array}{c}\text { Konsentrasi gas nitrogen } \\
\text { oksida (ppm) }\end{array}$ & $\begin{array}{c}\text { Tegangan keluaran sensor } \\
\text { MQ-135 (V) }\end{array}$ \\
\hline 1 & 6 & 0,03 \\
\hline 2 & 8 & 0,04 \\
\hline 3 & 9 & 0,05 \\
\hline 4 & 12 & 0,06 \\
\hline 5 & 15 & 0,07 \\
\hline 6 & 18 & 0,08 \\
\hline 7 & 23 & 0,09 \\
\hline 8 & 27 & 0,13 \\
\hline 9 & 32 & 0,16 \\
\hline 10 & 40 & 0,2 \\
\hline 11 & 47 & 0,23 \\
\hline 12 & 50 & 0,24 \\
\hline 13 & 57 & 0,29 \\
\hline
\end{tabular}




\begin{tabular}{lll}
\hline 14 & 62 & 0,3 \\
\hline 15 & 76 & 0,37 \\
\hline 16 & 88 & 0,43 \\
\hline 17 & 92 & 0,45 \\
\hline 18 & 103 & 0,5 \\
\hline 19 & 110 & 0,54 \\
\hline 20 & 129 & 0,63 \\
\hline
\end{tabular}

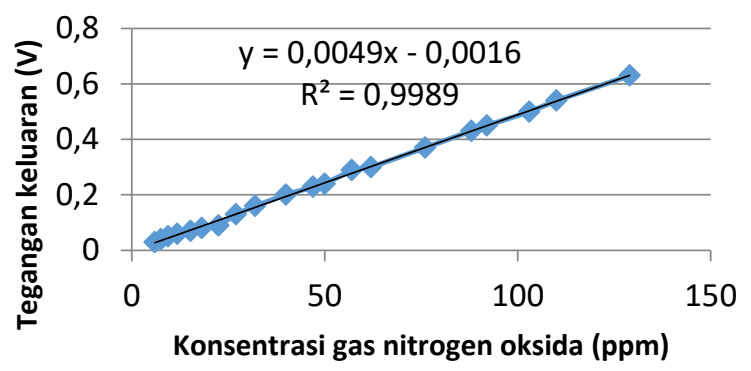

Gambar 9. Grafik hubungan konsentrasi gas nitrogen oksida dengan tegangan keluaran

Gambar 9. Menunjukkan bahwa semakin besar nilai sensor yang terdeteksi maka tegangan yang terbaca akan semakin tinggi. Hal ini ditunjukkan pada gambar dengan penaikan garis yang linier. Fungsi transfer pada grafik menunjukkan bahwa variasi konsentrasi gas nitrogen oksida sebanding dengan tegangan keluaran yang dihasilkan oleh sensor MQ-135 dengan nilai regresinya sebesar 0,9989 .

Pengujian sensor MQ-135 juga dilakukan dengan pembandingan yang didapat pada ISPU dan data konsentrasi gas nitrogen oksida yang telah didapatkan dari Dinas Lingkungan Hidup Kota Padang. Perbandingan dilakukan dengan membandingkan konsentrasi yang ada pada ISPU dengan konsentrasi gas nitrogen oksida terbaca oleh sensor MQ-135 yang telah deprogram menggunakan ESP32.

Tabel 4. 2 Perbandingan nilai konsentrasi gas nitrogen oksida dengan konsentrasi ISPU

\begin{tabular}{ccccc}
\hline Tanggal & Pukul & $\begin{array}{c}\text { Konsentrasi } \\
\text { gas NOx } \\
\text { pada sensor } \\
\text { MQ-135 } \\
\text { (ppm) }\end{array}$ & $\begin{array}{c}\text { Konsentrasi gas } \\
\text { NOx pada nilai } \\
\text { ISPU (ppm) }\end{array}$ & $\begin{array}{c}\text { Eror } \\
(\%)\end{array}$ \\
\hline $\begin{array}{c}11 \text { Oktober } \\
2020\end{array}$ & 15.01 & 6,11 & 5,31 & 15,07 \\
\hline $\begin{array}{c}12 \text { Oktober } \\
2020\end{array}$ & 15.01 & 6,91 & 5,31 & 30,13 \\
\hline $\begin{array}{c}13 \text { Oktober } \\
2020\end{array}$ & 15.17 & 5,58 & 5,31 & 5,08 \\
\hline $\begin{array}{c}14 \text { Oktober } \\
2020\end{array}$ & 15.01 & 5,78 & 5,31 & 8,85 \\
\hline $\begin{array}{c}15 \text { Oktober } \\
2020\end{array}$ & 15.01 & 5,63 & 5,31 & 6,03 \\
\hline $\begin{array}{c}16 \text { Oktober } \\
2020\end{array}$ & 15.01 & 5,38 & 5,31 & 1,32 \\
\hline $\begin{array}{c}17 \text { Oktober } \\
2020\end{array}$ & 15.02 & 5,53 & 5,31 & 4,14 \\
\hline $\begin{array}{c}18 \text { Oktober } \\
2020\end{array}$ & 15.01 & 5,42 & 5,31 & 2,07 \\
\hline & Eror rata-rata & & $9,09 \%$ \\
\hline
\end{tabular}

Eror rata-rata yang dihasilkan dari hasil perbandingan konsentrasi yang terbaca oleh sensor MQ-135 adalah 9,09\%. Hal ini menunjukkan bahwa sensor MQ-135 bekerja dengan baik dengan nilai konsentrasi nitrogen oksida yang terbaca mendekati nilai data dari ISPU. Tingginya nilai eror yang dihasilkan terjadi terhadap noise pada rangkaian serta waktu yang kurang tepat.

\section{Karakterisasi Sensor MQ-7}

Pengujian sensor MQ-7 dilakukan untuk mengetahui pengaruh dari variasi karbon monoksida. Sebelum digunakan untuk mendeteksi konsentrasi gas, sensor MQ-7 dipanaskan terlebih dahulu menggunakan tegangan $5 \mathrm{~V}$ dalam waktu 48 jam. Pengujian ini memperoleh hasil konsentrasi karbon monoksida, tegangan keluaran serta nilai Rs. Hasil dari variasi konsentrasi karbon monoksida dengan tegangan keluaran dapat dilihat pada Tabel 4.3.

Tabel 4.3 Hubungan konsentrasi gas karbon monoksida terhadap tegangan keluaran sensor MQ-7

\begin{tabular}{ccc}
\hline No & $\begin{array}{c}\text { Konsentrasi gas karbon } \\
\text { monoksida (ppm) }\end{array}$ & $\begin{array}{c}\text { Tegangan keluaran } \\
\text { sensor } \\
\text { MQ-7 (V) }\end{array}$ \\
\hline 1 & 6,09 & 0,81 \\
\hline 2 & 9,72 & 1,04 \\
\hline 3 & 14 & 1,25 \\
\hline 4 & 30,06 & 1,77 \\
\hline 5 & 54,39 & 2,24 \\
\hline 6 & 75,2 & 2,5
\end{tabular}

Tabel 4.3 Menghasilkan plot data tegangan keluaran terhadap konsentrasi gas karbon monoksida pada Gambar 4.2.

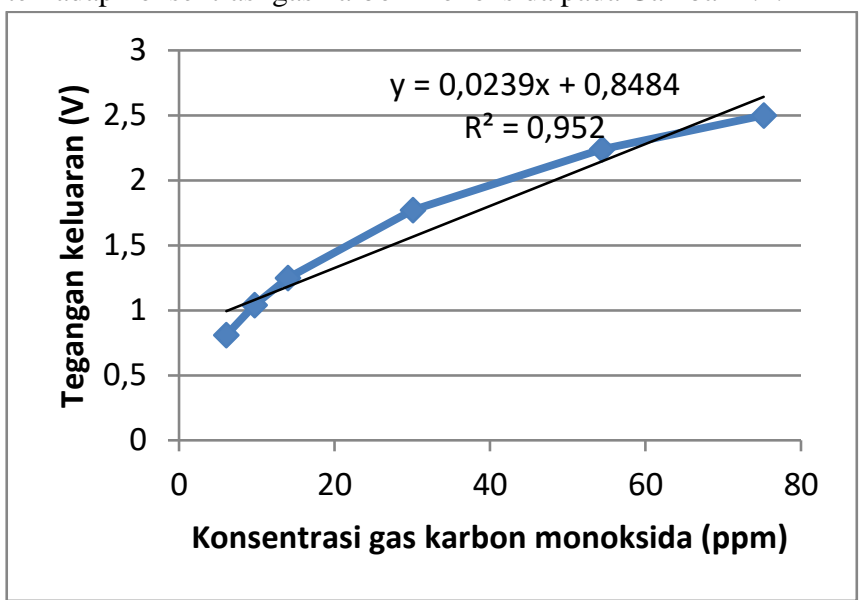

Gambar 4. 1 Grafik hubungan konsentrasi gas karbon monoksida dengan tegangan keluaran sensor MQ-7

Gambar 4.2 Menjelaskan mengenai hubungan antara konsentrasi gas karbon monoksida dengan tegangan keluaran. Hubungan ini membentuk grafik linier. Nilai regresi yang diperoleh sebesar 0,952 , nilai sensitivitas sensor sebesar 0,0239 V/ppm dengan tegangan offset sebesar 0,8484. Gambar 4.2 Menunjukkan bahwa setiap kenaikan konsentrasi gas karbon monoksida akan menyebabkan tegangan keluaran mengalami kenaikan pula.

Perbandingan nilai konsentrasi gas karbon monoksida dapat digunakan biogas analyzer. Penggunaan biogas analyzer bertujuan untuk mencari persentase eror dari sensor MQ-7. Pembandingan ini dilakukan dengan cara meletakkan sensor MQ7 yang terhubung dengan mikrokontroler dengan biogas analyzer 
agar dapat mendeteksi secara bersamaan nilai konsentrasi karbon monoksida yang dibuat menggunakan pembakaran sampah. Tabel 4. 4 Perbandingan konsentrasi gas karbon monoksida menggunakan sensor MQ-7 dengan biogas analyzer

\begin{tabular}{cccc}
\hline No & $\begin{array}{c}\text { Konsentrasi gas } \\
\text { CO pada sensor } \\
\text { MQ-7 }(\mathrm{ppm})\end{array}$ & $\begin{array}{c}\text { Konsentrasi gas } \\
\text { CO pada Biogas } \\
\text { Analyzer }(\mathrm{ppm})\end{array}$ & Eror (\%) \\
\hline 1 & 6,85 & 6 & 2,14 \\
\hline 2 & 8,87 & 8 & 10,88 \\
\hline 3 & 16,11 & 17 & 5,24 \\
\hline 4 & 30,06 & 29 & 3,66 \\
\hline 5 & 54,39 & 53 & 2,62 \\
\hline 6 & 60,25 & 59 & 2,32 \\
\hline 7 & 75,2 & 74 & 1,62 \\
\hline 8 & 109,79 & 108 & 1,66 \\
\hline 9 & 116,67 & 115 & 1,45 \\
\hline 10 & 126,34 & 125 & 1,07 \\
\hline & Eror rata-rata & & 3,26 \\
\hline
\end{tabular}

Tabel 4.5 Memperlihatkan bahwa untuk pengujian perbandingan konsentrasi gas karbon monoksida menggunakan sensor MQ-7 dan biogas analyzer adalah sebesar 3,26\%. Nilai eror rata-rata tersebut menunjukkan bahwa sensor MQ-7 dapat bekerja dengan baik dalam mendeteksi konsentrasi gas karbon monoksida. Beberapa kendala yang terjadi dalam pendeteksian gas karbon

\section{Pengujian ESP32}

Pengujian ESP32 dilakukan untuk mengetai bahwa telegram bot yang akan digunakan dapat bekerja dengan baik. Pengujian ini dilakukan dengan cara memasukkan program telegram bot pada ESP32.

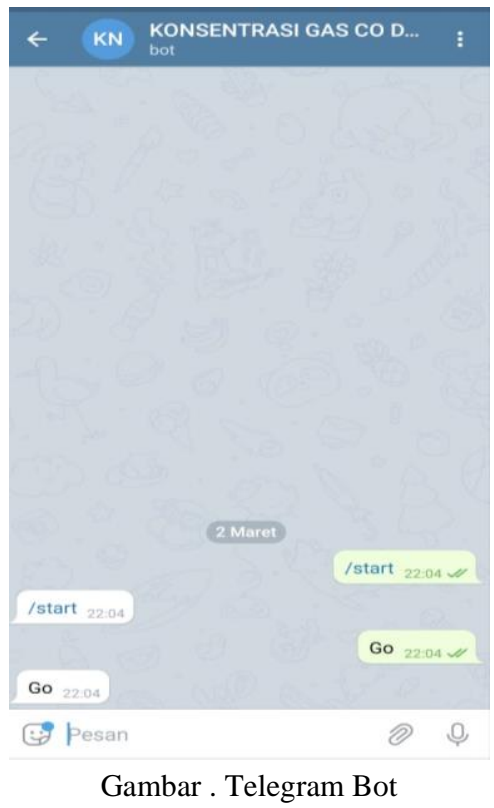

Gambar 4.4 menunjukkan bahwa ESP32 dapat terkoneksi pada WiFi yang tersedia serta telegram bot yang telah dibuat pada program arduino IDE dapat digunakan dengan baik dan bekerja dengan semestinya.

\section{Pengujian Modul Suara ISD1820}

Pengujian modul ISD1820 dilakukan untuk mengetahui bahwa modul ISD1820 dapat bekerja dengan baik. Durasi yang dapat digunakan untuk perekaman suara adalah 8 detik. Pengujian modul ISD1820 menghasilkan rekaman selama 8 detik dan bisa memutar kembali suara yang direkam dengan baik.

\section{Pengujian Keseluruhan Alat}

Pengujian alat secara keseluruhan bertujuan untuk mengetahui apakah alat yang telah di rangkai dapat bekerja dengan baik. Pengujian ini dilakukan dengan menggunakan sensor MQ-135, sensor MQ-7, modul ISD1820 ke ESP32 dan memprogramnya menggunakan Arduino IDE. Tujuan lain dari pengujian ini untuk mengetahui konsentrasi gas nitrogen oksida dan konsentrasi gas karbon monoksida yang dapat ditampilkan pada serial monitor dan telegram. Konsentrasi gas nitrogen oksida maupun karbon monoksida yang melebihi $50 \mathrm{ppm}$, akan mendapatkan notifikasi via telegram melalui telegram bot yang telah dibuat serta mengaktifkan modul ISD1820 sebagai bunyi peringatan.

Pengujian dilakukan dengan menvariasikan konsentrasi gas karbon monoksida dan nitrogen oksida yang dapat terdeteksi oleh sensor MQ-135 dan MQ-7. Nilai yang terdeteksi kurang dari 50 ppm dapat dicek menggunakan telegram bot secara langsung, sedangkan nilai konsentrasi gas yang melebihi $50 \mathrm{ppm}$ akan mengirimkan notifikasi ke smartphone yang telah mengikuti telegram bot. Selanjutnya, saat nilai konsentrasi gas melebihi 50 ppm, speaker yang terhubung dengan modul ISD1820 akan mengeluarkan bunyi yang telah direkam sebelumnya. Data alat keseluruhan dengan variasi konsentrasi gas dapat dilihat pada Tabel 4.7.

Tabel 4. 5 Data alat keseluruhan dengan variasi konsentrasi gas

\begin{tabular}{|c|c|c|c|}
\hline $\begin{array}{c}\text { Konsentrasi } \\
\text { gas } \\
\text { nitrogen } \\
\text { oksida } \\
\text { (ppm) }\end{array}$ & $\begin{array}{c}\text { Konsentrasi } \\
\text { gas karbon } \\
\text { monoksida } \\
\quad(\text { ppm })\end{array}$ & $\begin{array}{c}\text { Notifikasi } \\
\text { telegram } \\
\text { (ada/tidak) }\end{array}$ & $\begin{array}{c}\text { Speaker } \\
\text { (berbunyi } \\
\text { /tidak } \\
\text { berbunyi) }\end{array}$ \\
\hline 2,63 & 6 & Tidak ada & $\begin{array}{c}\text { Tidak } \\
\text { berbunyi }\end{array}$ \\
\hline 4,50 & 10 & Tidak ada & $\begin{array}{c}\text { Tidak } \\
\text { berbunyi }\end{array}$ \\
\hline 6,03 & 14 & Tidak ada & $\begin{array}{c}\text { Tidak } \\
\text { berbunyi }\end{array}$ \\
\hline 8,18 & 19 & Tidak ada & $\begin{array}{c}\text { Tidak } \\
\text { berbunyi }\end{array}$ \\
\hline 10,58 & 21 & Tidak ada & $\begin{array}{c}\text { Tidak } \\
\text { berbunyi }\end{array}$ \\
\hline 25,80 & 34 & Tidak ada & $\begin{array}{c}\text { Tidak } \\
\text { berbunyi }\end{array}$ \\
\hline 27,44 & 40 & Tidak ada & $\begin{array}{c}\text { Tidak } \\
\text { berbunyi }\end{array}$ \\
\hline 33,18 & 54 & Ada & Berbunyi \\
\hline 34,49 & 60 & Ada & Berbunyi \\
\hline 37,44 & 75 & Ada & Berbunyi \\
\hline 37,93 & 78 & Ada & Berbunyi \\
\hline 38,26 & 80 & Ada & Berbunyi \\
\hline 42,52 & 108 & Ada & Berbunyi \\
\hline 43,34 & 115 & Ada & Berbunyi \\
\hline 44,32 & 121 & Ada & Berbunyi \\
\hline
\end{tabular}

Tabel 4.7 Menunjukkan bahwa pengujian alat keseluruhan dapat terlaksana dengan baik. Saat salah satu nilai konsentrasi gas karbon monoksida dan nitrogen oksida melebihi 50 ppm, maka 
speaker akan berbunyi dan smartphone akan mendapatkan notifikasi oleh telegram.

\section{KESIMPULAN}

Berdasarkan hasil serta analisa yang telah dilakukan pada penelitian ini, dapat disimpulkan bahwa:

1. Rancang bangun alat pendeteksi NOx dan CO berbasis notifikasi dan suara telah berhasil dibuat dan dapat bekerja dengan baik.

2. Karakterisasi sensor MQ-135 dengan perbandingan konsentrasi gas nitrogen oksida terhadap tegangan keluaran didapatkan fungsi transfer $\mathrm{y}=0,0049 \mathrm{x}-0,0016$ dengan nilai regresi adalah 0,9989 .

3. Karakterisasi sensor MQ-135 dilakukan dengan perbandingan data yang diperoleh dari dinas lingkungan hidup Kota padang, didapatkan nilai persentase eror sebesar $9,09 \%$.

4. Karakterisasi sensor MQ-7 dengan perbandingan antara konsentrasi gas karbon monoksida dengan tegangan keluaran diperoleh fungsi transfer $\mathrm{y}=0,239 \mathrm{x}+0,8484$ dengan nilai regresi sebesar 0,952 .

5. Nilai eror yang didapatkan melalui perbandingan hasil konsentrasi gas karbon monoksida yang di deteksi oleh sensor MQ-7 dengan Biogas analyzer adalah 3,26\%.

6. Pengujian ESP32 untuk dapat terhubung dengan telegram bot dapat bekerja dengan baik.

\section{REFERENCES}

[1] Andrianto, H., 2016, Arduino Belajar Cepat dan Pemrograman, INFORMATIKA, Bandung

[2] Dewata, I., dan Tarmizi, 2015, Kimia Lingkungan, UNP Press, Padang.

[3] Ezoe, S., 1997, The Study on Integrated Air Quality Management for Jakarta Metropolitan Area, Nippon Koei CO \& Suuri Keikaku CO, Japan.

[4] Fahana, J., Umar, R., Ridho, F., 2017, Pemanfaatan Telegram Sebagai Notifikasi Serangan untuk Keperluan Forensik Jaringan, QUERY : Jurnal Sistem Informasi, Vol. 1, No. 2, Hal. 6-14.

[5] Giancoli, D.C., 2014, FISIKA : Prinsip dan Aplikasi, Erlangga, Jakarta.

[6] Hantaro, G.D., 2009, WiFi (Wireless LAN), Informatika, Bandung.

[7] Hickman, A.J., 1999. Methodology for calculating transport emissions and energy comsumption, transport research laboratory.

[8] Ismiyati, 2014, Pencemaran Udara Akibat Emisi Gas Buang Kendaraan Bermotor, Jurnal Manajemen Transportasi \& Logistic, Vol. 01, Hal. 241-248.

[9] Junus, M., 2016, Rancang Bangun Sistem Monitoring Tingkat Pencemaran Udara (Gas Buang) CO/NO2 Secara Mobile Berbasis Web di Kota Malang, Prosiding SENTIA, Vol. 08, No. 02, Hal. 116-122.
[10] Kustaman, R., 2017, Bunyi dan Manusia, ProTVF, Vol. 1, No. 2.

[11] Mahdalena, F., H., 2020, Rancang Bangun Sistem Monitoring Asap Rokok di Toilet Sekolah Menggunakan Sensor MQ-7 dan Transceiver nRF24L01+ dengan Output Suara Berbasis Modul ISD1820, Skripsi, Universitas Andalas, Padang.

[12] Marazola, N.T., Setiawan, F.B., 2020, Alat Pembaca Tegangan Otot yang Terintegrasi dengan Bluetooth 4.0 Menggunakan ESP32, Prosiding Seminar Nasional Teknik Elektro, Vol. 5, No. 1, Hal. 7-12.

[13] Menteri Lingkungan Hidup dan Kehutanan Republik Indonesia, 2020, Peraturan Menteri Lingkungan Hidup dan Kehutanan Republik Indonesia Nomor P.14/MENLHK/SEKJEN/KUM.1.7.2020 Tentang Indeks Standar Pencemaran Udara, Menlhk, Jakarta.

[14] Nurkholis, Junaidi, Surtono, A., 2014, Rancang Bangun Sistem Akuisisi Data Resonansi Gelombang Bunyi Menggunakan Transduser Ultrasonik Berbasis Mikrokontroler ATMega8535, Jurnal Teori dan Aplikasi Fisika, Vol. 02, No. 02, Hal.165-169 .

[15] Ohoiwutun, J., 2018, Analisis dan Perancangan Smart Dump Menggunakan Arduino Mega 2560 Rev3 dan GSM SIM900, Jurnal Electro Luceat, Vol. 4, No. 1, Hal. 1-11.

[16] Ozkan, S.U., Agarwal, S.K., Marcelin, G., 1995, Reduction of Nitrogen Oxide Emissions, American Chemical Society, California.

[17] Sears, F.W., dan Zemansky, M., 1999, Fisika untuk Universitas I (Mekanika, Panas, dan Bunyi), Trimitra Mandiri, Jakarta.

[18] Wicaksono, H.A., 2017, Rancang Bangun Sistem Monitoring Konsentrasi Gas Nitrogen Oksida (NOx) Sebagai Emisi Gas Buang Menggunakan Sensor Gas MQ135 Berbasis Mikrokontroler STM32F4 discovery, Tugas Akhir, Institut Teknologi Sepuluh November.

[19] Wicaksono, M.F., Rahmatya, M.D., 2020, Implementasi Arduino dan ESP32 CAM untuk smart home. Jurnal Teknologi dan Informasi, Vol. 10, No.1, Hal. 40-51.

[20] Yusro, M., Diamah, A., 2019, Sensor dan Transduser (Teori dan Aplikasi), Universitas Negeri Jakarta, Jakarta. 